\title{
Absorption of Free and Peptide-Linked Glycine and Phenylalanine in Children with Active Celiac Disease
}

\author{
W. NÜTZENADEL, ${ }^{(30)}$ K. FAHR, AND P. LUTZ \\ University of Heidelberg, Children's Hospital, Im Neuenheimer Feld 150, Heidelberg, Germany
}

\begin{abstract}
Summary
Using a marker perfusing technique, the jejunal absorption rates of glycine and phenylalanine from test solutions containing either the free amino acids or glycyl-phenylalanine $(30 \mathrm{mM}$ each) were studied in five children with active celiac disease and in three controls. Changes in plasma amino acid levels during intestinal loading were also investigated.

Mean values of intestinal uptake rates $(\mu \mathrm{moles} / \mathrm{min} / 20 \mathrm{~cm}$ segment) in patients and controls were found to be as follows: free glycine, $19.3 \pm 21.8$ and $74.5 \pm 10.3$; peptide-linked glycine, 45.0 \pm 12.4 and $110.7 \pm 20.1$; free phenylalanine, $33.6 \pm 19.6$ and 106.1 \pm 10.6; peptide-linked phenylalanine, $44.5 \pm 14.3$ and $113.6 \pm$ 11.1, respectively.

Thus, amino acid absorption is higher from peptide-linked glycine and phenylalanine, and the advantage of individual amino acid absorption from dipeptide seems to be maintained in the disease state.

Changes of amino acid levels in plasma do not reflect impaired intestinal absorption because the levels of phenylalanine increased to the same extent in patients and in controls, and the increment of glycine was found to be higher in the patients group.
\end{abstract}

\section{Speculation}

The dipeptide absorption pathway contributes to amino acid uptake in controls as well as in patients with reduced intestinal absorptive capacity. Therefore, dietary formulae (elemental diet) used for the treatment of malnutrition due to intestinal disease should contain not only free amino acids but oligopeptides as well.

Ample evidence has accumulated that the intestinal absorption of amino acids is accomplished by the uptake of free amino acids and the mucosal transfer of oligopeptides as well $(17,18)$. In intestine of several species $(19,20,24)$ and of man $(3,4,7,11)$ a distinct transport system serving the uptake of dipeptides has been identified and well characterized $(2,19)$. Accordingly, the absorption pathway for dipeptides contributes to nitrogen and amino acid uptake during protein digestion, but the significance of free versus peptide-linked amino acid absorption is still a matter of debate.

Findings in patients with inborn errors of membrane transport in kidney and intestine involving absorption of neutral or dibasic amino acids emphasize the importance of dipeptide absorption because uptake of peptide-linked amino acids was found to be unimpaired in gut allowing adequate amino acid nutrition of the affected patients $(5,12)$. Similar observations have been reported in adult patients with celiac disease $(1,14,27)$. Using a marker perfusion technique, the intestinal absorption rate of amino acids from dipeptide was found to be normal or less severely impaired than the markedly reduced absorption of free acids. This unequal impairment of absorptive function is remarkable in view of the severe morphologic lesion of the intestinal mucosa combined with malabsorption of many nutrients in this disease.

In children with active celiac disease growth retardation, underweight and protein deficiency are frequently encountered but knowledge is scanty as to which extent malabsorption of amino acids contributes to these symptoms. Regarding the requirements of nitrogen and essential amino acids to maintain growth and weight gain in children, the form in which proteins are most easily absorbed in the disease state seems to be of great interest. The purpose of our study was, first, to determine the degree of impaired amino acid absorption and, second, to compare absorption rates of free versus peptide-linked amino acids in children with active celiac disease.

\section{MATERIALS AND METHODS}

Seven children in whom celiac disease was diagnosed during infancy were investigated for relapse after they had discontinued the gluten-free diet for at least 3 years. Their age at time of investigation ranged from 10 to 15 years. Clinical symptoms were absent or minimal in all but one who was suffering from chronic diarrhea and underweight. In five children, examinations revealed an abnormal xylose test and a flat mucosa in the intestinal biopsy. According to present understanding, gluten-sensitive enteropathy was most likely responsible for the mucosal changes observed. Two of them showed no evidence of the disease by clinical or laboratory examinations, and the intestinal biopsy revealed a normal histologic appearance of the mucosa. These two children and one of the authors served as controls. One of the former patients was reinvestigated after 3 years on a gluten-free diet. At that time, mucosal alterations had returned to an almost normal picture. Parents and children gave fully informed consent to the study which was approved by the local Ethical Committee.

\section{EXPERIMENTAL PROCEDURE}

A double lumen tube with two openings (distance, $20 \mathrm{~cm}$ ) was introduced into the jejunum via nasal route on the evening before the experiment and remained there for the next 2 days. The proximal opening was placed near the duodenojejunal junction, and the distal orifice reached the second or third loop of jejunum. The perfusion experiments either with the free amino acid or with the dipeptide were performed on the following 2 days between 9 and $11 \mathrm{AM}$. The perfusion solutions consist of sodium chloride (120 mval/liter), polyethylenglycol ( $2 \mathrm{~g} / \mathrm{liter})$, and either glycine together with phenylalanine or of glycyl-phenylalanine $(30$ 
mmoles/liter each). The perfusion solution was introduced into the tube with the proximal opening by a peristaltic pump at a constant rate of $5 \mathrm{ml} / \mathrm{min}$. Total amount of amino acids or dipeptide infused were $15 \mathrm{mmoles} / \mathrm{m}^{2}$ body surface. Two samples of intestinal fluid were collected between 40 and 50 and between 60 and $70 \mathrm{~min}$ after beginning of the infusion through the tube with the distal orifice by simple syphonage or slight aspiration. Blood samples were drawn at the beginning and end of the infusion.

\section{CHEMICAL ANALYSIS}

Concentrations of amino acids in plasma and intestinal aspirates were determined on an amino acid analyser (Biocal BC 202) with a program suitable to separate glycyl-phenylalanine as a single peak.

Polyethylene glycol was determined according to described methods $(13,15)$. To minimize errors due to binding of polyethylene glycol to the wall of the vials samples of the infusion solution were taken and kept under the same condition as the intestinal aspirates and were used to make up appropriate dilutions for the standard curve of the polyethylene glycol estimations. Further polethylene glycol was determined at least $48 \mathrm{hr}$ after the experiments were performed.

\section{CALCULATION OF DATA}

The disappearance rates from test solutions containing either free amino acids or the dipeptide were calculated by an equation previously described (3), and results are expressed as the amount of amino acids absorbed in $\mu$ moles $/ \mathrm{min} / 20 \mathrm{~cm}$ segment. The increase of plasma levels of glycine and phenylalanine was calculated from the difference of amino acid levels in plasma at the beginning and end of the experiments. Statistical significance was analyzed by Student's $t$ test. Hydrolytic activity towards glycylphenylalanine was determined in three samples of intestinal fluid taken before the experiments were started and was found to be around $0.7 \mu \mathrm{moles} / \mathrm{min} / \mathrm{ml}$ ( $15 \mathrm{mM}$ glycyl-phenylalanine; $15 \mathrm{~min}$ incubation time at $20^{\circ} \mathrm{C}$ ).

\section{MATERIALS}

Glycine, phenylalanine, and polyethylene glycol (molecular weight, 2000 to 4000 ) were obtained from Merck (Darmstadt, Germany), and glycyl-phenylalanine was purchased from Fluka (Buchs, Switzerland).

\section{RESULTS}

Table 1 shows the medium values of the two determinations in each proband. The absorption capacity of free and peptide-linked amino acids in active celiac disease is reduced to rates being 30 to $40 \%$ of the mean values observed in the control group. Considerable individual variations in the ability to absorb amino acids or dipeptide are evident, but in general, those patients with very low uptake of free amino acids also exhibited the most severe impairment of dipeptide absorption. Thus, the degree of impaired absorption seems to be almost equal for free and peptide-linked glycine and phenylalanine, but it should be noted that at least glycine absorption is higher from the dipeptide compared to that from the free amino acid. The statistical evaluation of this difference shows a $P$ value at the 0.05 confidence levels for the patients and a level below 0.05 for the controls. Phenylalanine absorption is only slightly different.

Absorption rates of the two determinations in a single experiment varies markedly in patients while duplicates of the controls are close. Gut motility is affected in celiac disease, and therefore, flow rates of the perfusion solution may be less constant in patients causing the observed fluctuation. The reinvestigation of one patient after 3 years on a gluten-free diet shows that impaired absorptive function has returned to normal; in fact, values are found in the range of controls (Table 1).

One is surprised that the markedly reduced intestinal absorption in the upper jejunum of glycine and phenylalanine does not result in a smaller increase of these amino acids in plasma (Table 2). Changes of phenylalanine are very similar in patients and controls, whereas increase of glycine tends to be higher in the patient group. The design of the experiments - constant infusion rate per min, amino acid load related to body surface, and collection of blood at the beginning and the end of infusion--implies that times at

Table 1. Disappearance rates ( $\mu$ moles $/ \mathrm{min} / 20 \mathrm{~cm}$ jejunal segment) of glycine and phenylalanine from test solutions containing either free amino acids or glycyl-phenylalanine ${ }^{1}$

\begin{tabular}{|c|c|c|c|c|}
\hline & \multicolumn{2}{|c|}{ 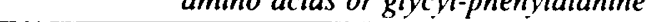 } & & \\
\hline & & & & \\
\hline & Free & Dipeptide & Free & Dipeptide \\
\hline
\end{tabular}

\section{Controls}

B. K.
W. N.
M. K.

$\begin{array}{lr}64.5 & 103.2 \\ 73.9 & 133.5 \\ 85.2 & 95.6 \\ & \end{array}$

$$
74.5 \pm 10.3^{2}
$$

$110.7 \pm 20.05$

$\begin{array}{rl}94.7 & 103.6 \\ 108.0 & 125.5 \\ 116.8 & 111.1 \\ 106.1 \pm 10.6 & 113.6 \pm 11.1\end{array}$

Patients with active disease

$\begin{array}{lrlll}\text { K. S. } & 55.3 & 63.9 & 60.7 & 68.4 \\ \text { F. A. } & 24.8 & 51.7 & 40.0 & 45.3 \\ \text { M. H. } & 7.6 & 38.3 & 11.3 & 30.85 \\ \text { H. K. } & 4.9 & 35.5 & 38.6 & 37.5 \\ \text { E. M. } & 4.1 & 35.8 & 17.8 & 40.9 \\ & 19.3 \pm 21.8 & 45.0 \pm 12.4 & 33.6 \pm 19.6 & 44.5 \pm 14.3\end{array}$

Patient treated

\footnotetext{
K. S.

' Values are the medium of two determinations in each patient.

2 Mean \pm S.D. of patients and controls.
} 
Table 2. Plasma levels of glycine and phenylalanine at the beginning of the experiments $\left(t_{0}\right)$ and increase $(\Delta)$ of the amino acids during intestinal perfusion ${ }^{1}$

\begin{tabular}{|c|c|c|c|c|c|c|c|c|}
\hline & \multicolumn{4}{|c|}{ Glycine ( $\mu$ moles/liter) } & \multicolumn{4}{|c|}{ Phenylalanine ( $\mu$ moles/liter) } \\
\hline & \multicolumn{2}{|c|}{ Controls } & \multicolumn{2}{|c|}{ Patients } & \multicolumn{2}{|c|}{ Controls } & \multicolumn{2}{|c|}{ Patients } \\
\hline & $t_{0}$ & $\Delta$ & $t_{0}$ & $\Delta$ & $t_{0}$ & $\Delta$ & $t_{1}$ & $\Delta$ \\
\hline Free & $0.224 \pm 0.063^{2}$ & $0.385 \pm 0.122$ & $0.168 \pm 0.061$ & $0.210 \pm 0.090$ & $0.045 \pm 0.007$ & $0.421 \pm 0.107$ & $0.042 \pm 0.003$ & $0.491 \pm 0.031$ \\
\hline Peptide & $0.231 \pm 0.071$ & $0.356 \pm 0.091$ & $0.205 \pm 0.012$ & $0.237 \pm 0.071$ & $0.057 \pm 0.008$ & $0.432 \pm 0.123$ & $0.057 \pm 0.015$ & $0.480 \pm 0.081$ \\
\hline
\end{tabular}

'No statistical significance is evident if patients and controls are compared.

${ }^{2}$ Mean \pm S.D.

Table 3. Plasma levels of certain amino acids at the beginning of the experiments

\begin{tabular}{lcc}
\hline & \multicolumn{1}{c}{ Patients } & Controls \\
\hline Threonine & $0.073 \pm 0.021^{2}$ & $0.076 \pm 0.016$ \\
Serine & $0.112 \pm 0.028$ & $0.090 \pm 0.006$ \\
Alanine & $0.374 \pm 0.113$ & $0.253 \pm 0.094$ \\
Valine & $0.161 \pm 0.029$ & $0.214 \pm 0.034$ \\
Methionine & $0.019 \pm 0.002$ & $0.021 \pm 0.003$ \\
Leucine & $0.094 \pm 0.014$ & $0.124 \pm 0.011$ \\
Tyrosine & $0.037 \pm 0.006$ & $0.046 \pm 0.002$ \\
\hline
\end{tabular}

' Differences between patients and controls are not statistically valid.

${ }^{2}$ Mean \pm S.D. (mmoles/liter).

which the second blood sample was drawn differ slightly from one proband to another. It seems conceivable that results of repeated determinations of plasma levels during infusion may exhibit a delayed increase of plasma amino acids in patients.

Glycine and phenylalanine in plasma at the beginning of the experiments are very similar in patients and controls (Table 2 ). The mean values of certain other amino acids are slightly different (Table 3 ), and the differences show a tendency toward the distorted amino acid profile observed in protein calorie malnutrition (16). The changes are characterized by relative deficiencies of branched-chain amino acids as well as relative elevations of some nonessential amino acids. The altered endogenous metabolism may influence the amino acid profile after the intestinal loading test, and this may be relevant to the observation of a similar increase of amino acids in patients and controls.

\section{DISCUSSION}

The processes that are concerned with the absorption of glycylphenylalanine are not fully elucidated by this study, but findings suggest that intraluminal hydrolysis does not precede the absorption of amino acids from dipeptide. Although hydrolysis of glycylphenylalanine by brush border enzymes has been demonstrated (21), human intestinal fluid shows only a low hydrolytic activity. Taking into account the in vitro activity of $0.7 \mu \mathrm{moles} / \mathrm{min} / \mathrm{ml}$ intestinal fluid and the amount of peptide infused $(150 \mu$ moles/ min), only a small percentage could be hydrolyzed in the lumen of the gut. Accordingly, the bulk of amino acids recovered in the samples taken during infusion of the dipeptide are peptide linked (more than $85 \%$ ). Further, the absorption rates for glycine and phenylalanine from dipeptide are very similar but different if free glycine and phenylalanine are infused.

Surface hydrolysis linked to the uptake mechanism of free amino acids have not been excluded in these experimental conditions but data suggest that the absorptive mechanism is at least partially accomplished by a distinct mode of uptake not serving the entry of free amino acids.

To our knowledge, amino acid absorption from dipeptide has not been studied in children before, but the findings of this study suggest a similar mechanism as has been described for several dipeptides in adults $(3,4,23)$. Our observations indicate that the intestinal absorption of free and peptide-linked amino acids is equally impaired if the absorbing surface is reduced. Thus, we failed to confirm findings in adult patients which show that the capacity to absorb amino acid from dipeptide is better retained (1.27). This discrepancy could otherwise be due to variations of the technique used or to the different dipeptide infused than to different age.

More important seems the fact that dipeptides are substrates of amino acid transport even if the absorptive surface is reduced and that their uptake may be preferential to that of free acids. This may have therapeutic implications because current treatment of malnutrition due to intestinal disease includes dietary formulae containing mainly free amino acids (15). In view of these findings, a mixture containing free and peptide-linked amino acids could be more advantageous. This conclusion may be precocious in view of the several hundred dipeptides which are released during protein hydrolysis in intestine and of which absorption rates are unknown. Further studies are required to substantiate this suggestion.

Increments of plasma amino acid levels after intestinal loading with amino acids, peptides, or proteins have been previously studied and results have shown higher $(10)$, lower $(6,8,25)$, or similar (22) increase if patients and controls are compared. The marker perfusion technique allows the assessment of absorption close to the site of the uptake mechanism, and the absorption defect in proximal intestine of children with active celiac disease seems to be unequivocal.

On the other hand, only one segment of gut is under investigation by this technique, and changes of plasma levels may reflect the absorptive capacity of the whole intestine. Interestingly, in adult patients with celiac disease, methionine absorption was found to be reduced in proximal intestine but enhanced distally (26). Therefore, the observations about changes of plasma levels during loading tests are not necessarily unreliable with respect to absorptive function. Malabsorption of amino acids and their nutritional consequences may be less grave than results of the marker perfusion technique in the upper intestine indicate.

\section{REFERENCES AND NOTES}

1. Adibi, S. A., Fogel, M. R., and Agrawal. R. M.: Comparison of free amino acid and dipeptide absorption in the jejunum of sprue patients. Gastroenterology. 67: 586 (1974).

2. Adibi, S. A.: Evidence for two different mode of tripeptide disappearance in human intestine uptake by peptide carrier systems and hydrolysis by peptide hydrolases. J. Clin. Invest.. 56: 1355 (1975).

3. Adibi. S. A., and Morse, E. L.. Intestinal transport of dipeptide in man: relative importance of hydrolysis and intact absorption. J. Clin. Invest., $58: 2266$ (1971)

4. Adibi. S. A.. and Soleimanpour. M.: Functional characterization of dipeptide transport system in human jejunum. J. Clin. Invest. $53: 1368$ (1974).

5. Asatoor. A. M.. (heng. B.. F.dwards. K. D. (i.. Lant. A. F.. Matthews. D. M. Milne. M. D., Navab, F.. and Richards. A. J.: Intestinal absorption of two dipeptides in Hartnup disease. (jut. 11:380 (1970).

6. Butterworth. C. E., Santini, R., and Perez-Santiago, E.: The absorption of glycinc and its conversion to serine in patients with sprue. J. ('lin. Invest.. 37: 20 (1958).

7. Cook. (j. C.: Independent jejunal mechanism for glycine and glycylglycine transfer in man in vivo. Br. J. Nutr.. 31): 13 (1973).

8. Craft. J. L.. Geddes. D.. Hyde. ( $:$ W.. Wise. J. J., and Matthews, D. M. Absorption and malabsorption of glycine and glycine peptides in man. (iut. "9 
$425(1968)$

9. Crane, C. W. and Neuberger, A.: Absorption and elimination of ${ }^{15} \mathrm{~N}$ after administration of isotopically labelled yeast protein and yeast hydrolysate to adult patients with coeliac disease. I. Rate of absorption of '" $\mathrm{N}$ yeast protein and yeast protein hydrolysate. Br. Med. J., 2: 815 (1960).

10. Douglas. A. P.. and Booth. C. C.: Postprandial plasma-free amino acids in adult coeliac disease after oral gluten and albumin. Clin. Sci., 37: 643 (1969).

11. Fairclough. P. D.. Silk. D. B. A., Clark, M. L., Matthews, D. M.. Maris, T. C. Burston. D.. and Clegg. K. M.: Effect of glycylglycine absorption from human jejunum of a amino acid mixture simulating casein and a partial enzymic hydrolysate of casein containing small peptides. Clin. Sci. Mol. Med.. 53: 27 (1977).

12. Hellier. M. D., Holdworth, C. D. Perrett, D., and Thirum Rai, C.: Intestinal dipeptide transport in normal and cystinuric subjects. Clin. Sci.. 43: 659 (1972).

13. Hyden. S.: Turbidometric method for determination of higher polyethylencycols in biological materials. Ann. Rev. Agricoll. Sweden, 22: 139 (1955).

14. Klippstein. F. S.. and Corcino. J. J.: Malabsorption of essential amino acids in tropical sprue. Gastroenterology, 68: 239 (1975).

15. Malawer, S. J.. and Powell. D. W.: An improved turbidometric analysis of polyethylene glycol utilizing an emulsifier. Gastroenterology, 65: 192 (1967).

16. Mc Laren. D. S.. Kamel. W. S.. and Ayyoub, N.: Plasma amino acids and the detection of protein-caloric malnutrition. Am. J. Clin. Nutr., 17: 152 (1965).

17. Matthews. D. M.: Intestinal absorption of peptides. Physiol. Rev., 55: 537 (1975).

18. Matthews. D. M.: Protein absorption. J. Clin. Pathol. 24 (Suppl. 5): 29 (1971)

19. Matthews. D. M.. Gandy, R. H.. Taylor. E., and Burston. D. H.: Influx of two dipeptides, glyclsarcosine and L-glutamyl-L-glutamic acid, into hamster jejunum in vitro. Clin. Sci. Mol. Med.. 56: 15 (1979).

20. Nützenadel. W., and Scriver, S. R.: Uptake and metabolism of $\beta$-alanine and Lcarnosine by rat tissues in vitro: role in nutrition. Am. J. Physiol., 230: 643

Copyright $(C) 1981$ International Pediatric Research Foundation, Inc. $0031-3998 / 81 / 1504-0309 \$ 02.00 / 0$

\section{(1976)}

21. Quandalini, S., and Rubino, A.: Uptake of phenylalanine and glycyl-L-phenylalanine by intestinal mucosa and developing rabbits. Acta Paediatr. Belg., 30: 198 (1977).

22. Richmond, J., and Girwood, R. H.: Observations on amino acid absorption. Clin. Sci., 22: 301 (1962)

23. Rubino, A., and De Vizia, B.: Dipeptide transport across the brush border of human smail intestine. Acta Paediatr. Scand., 64: 151 (1975).

24. Rubino, A., Field, M., and Shwachman. H.: Intestinal transport of amino acid residue of dipeptides. I. Influx of glycine residues of glycylproline across mucosal border. J. Biol. Chem., 246: 3542 (1971).

25. Sadakili. F.: Dipeptidase deficiency and malabsorption of glycyl-glycine in disease state. Gut, 12: 276 (1971).

26. Schedl, H. P.. Pierce, C. E. Prider, A. and Clifton, J. A.: Absorption of Lmethionine from the human small intestine. J. Clin. Invest., 47: 417 (1968).

27. Silk, D. B. A.. Kumar, P. J., Perrett, D.. Clark, M. L., and Dawson, A. M.: Amino acid and peptide absorption in patients with celiac disease and dermatitis herpetiformis. Gut, 15: I (1974).

28. Thompson. W. R. Stephens, R. V.. Randall, H. T., and Bowen, J. R.: Use of the "space diet" in the management of a patient with extreme short bowel "space diet" in the management of a
syndrome. Am. J. Surg.. II7: 449 (1969).

29. The authors thank Mrs. Weber for her assistance in performing amino acid and peptide analyses and Mrs. I. Schweizer for typing the manuscript.

30. Requests for reprints should be addressed to: Dr. W. Nützenadel, Children's Hospital. University of Heidelberg, Im Neuenheimer Feld 150,6900 Heidelberg. Germany.

31. This research was supported by a grant of Deutsche Forschungsgemeinschaft

32. Received for publication April 2, 1980.

33. Accepted for publication August 13, 1980 